\title{
SPORT: uma concepção emergente no jornal kolonie
}

\author{
Alice Beatriz Assmann? \\ Janice Zarpellon Mazo² \\ Carolina Fernandes da Silva ${ }^{3}$
}

\section{RESUMO}

Este estudo busca investigar as concepções do termo sport (esporte) veiculadas pelo jornal Kolonie no início do século XX. Para tanto, foram coletadas reportagens do jornal Kolonie, periódico veiculado em idioma alemão e destinado aos teuto-brasileiros da cidade de Santa Cruz do Sul e circunvizinhanças, no estado do Rio Grande do Sul. A interpretação das fontes evidenciou que o registro do termo sport, em língua inglesa, pelo jornal ocorreu a partir de 1900, quando são aludidas práticas esportivas com representações identitárias diferenciadas das teuto-brasileiras. Na década de 1910, o termo sport aparece com maior recorrência nas reportagens que abordam o futebol e a fundação de clubes específicos para esta prática. Para além deste esporte, discursos associados a representações higienistas e de modernidade emergiram no cenário esportivo de Santa Cruz do Sul, alcançando associações esportivas de tênis e ginástica.

Palavras-chave: História do Esporte. Futebol. Teuto-brasileiros. Jornalismo Esportivo.

1 Doutoranda em Ciências do Movimento Humano. Universidade Federal do Rio Grande do Sul (UFRGS). Porto Alegre/Rio Grande do Sul, Brasil. E-mail: alice.assmann@gmail.com

2 Doutora em Ciências do Desporto. Professora da Escola de Educação Física, Fisioterapia e Dança da Universidade Federal do Rio Grande do Sul (ESEFID/UFRGS). Porto Alegre/Rio Grande do Sul, Brasil.

E-mail: janice.mazo@ufrgs.br

3 Doutora em Ciências do Movimento Humano. Professora da Universidade Federal de Viçosa (UFV). Viçosa/ Minas Gerais, Brasil. E-mail: carol_ed.fis@hotmail.com 


\title{
SPORT: an emerging concept in the newspaper Kolonie
}

\begin{abstract}
This research aims to investigate the concepts of the term "sport" circulated by the Kolonie newspaper at the beginning of the 20th century. For this purpose, reports were collected from Kolonie, a newspaper published in German and directed to the GermanBrazilian citizens from Santa Cruz do Sul city and surroundings. The interpretation of the sources evidenced the appropriation of the term "sport", in the English language, by the newspaper was in 1900, when new sporting practices took place, distinguished from the German-Brazilian representations of identity. In the 1910s, the term "sport" was recurring, especially, in reports concerning football and specific clubs to this practice. Beyond this sport, speeches relating hygienist and modern representations emerged at the Santa Cruz's sports scene, reaching associations of tennis and gymnastic.
\end{abstract}

Keywords: History of sport. Football. German-brazilian. Sports journalism

\section{SPORT: una concepción emergente en el diario Kolonie}

\section{RESUMEN}

Este estudio tiene como objetivo investigar las concepciones del término sport (deporte) transmitido por el diario Kolonie al comienzos del siglo XX. Por lo tanto, se recogieron los informes periódicos del Kolonie, transmitido en idioma alemán y destinado a la ciudad teuto-brasileña de Santa Cruz do Sul y a su alrededor, en Rio Grande do Sul. La interpretación de las fuentes revelaron que el registro del término deporte el periódico se produjo después de 1900, cuando se alude prácticas deportivas con diferentes representaciones de identidad del teuto-brasileñas. En la década de 1910, el sport parece más recurrencia en los informes que hablan de fútbol y la fundación de clubes específicos para practicar. Además de este deporte, emergieron discursos asociados a representaciones higienistas y modernas en la escena deportiva santa-cruzense, alcanzando asociaciones deportivas de tenis y gimnasia.

Palabras clave: Historia del deporte. Fútbol. Teuto-brasileño. Periodismo deportivo 


\section{INTRODUÇÃO}

As relações que emergem da parelha 'esporte e mídia impressa' são fenômenos interdisciplinares relevantes para estudiosos tanto do esporte como das áreas de Comunicação Social. O envolvimento da mídia no cenário esportivo atual é notável; no entanto, como as práticas esportivas e os jornais se relacionavam nos finais do século XIX e início do século XX, no Brasil, ainda merece uma maior atenção.

Destarte, este estudo 4 busca investigar as concepções do termo sport (esporte) veiculadas pelo jornal Kolonie, de Santa Cruz do Sul, no início do século XX. Santa Cruz do Sul é uma das cidades sul-rio-grandenses, onde houve protagonismo dos teuto-brasileiros no campo esportivo. E, o jornal Kolonie, editado nesta cidade, mas com alcance nas circunvizinhanças, desempenhou um papel significativo na disseminação das notícias sobre as associações e práticas esportivas. Este jornal era redigido em idioma alemão, mas quando se referia a determinadas práticas esportivas empregava o termo em língua inglesa, ou seja, sport (esporte).

A criação do jornal Kolonie ocorreu pela iniciativa de um grupo de teuto-brasileiros que se reuniram em uma sala do Clube União, no Bairro Centro da cidade de Santa Cruz do Sul, no final do ano de 1890 (DIE 1. ORDENTL. GENERALVERSAMMLUNG, 1891). O Kolonie, segundo Weschenfelder (2010), foi um dos primeiros periódicos "fortes" editados em língua alemã nas regiões interioranas do Rio Grande do Sul, relacionando tal condição ao grupo coeso e "com condições" que idealizou o jornal. Talvez, tenha influenciado a criação de outros jornais, pois no período começaram a circular outros periódicos voltados a grupos étnicos específicos (HOHFELDT, 2006).

O Kolonie, desde sua primeira edição em 1891 era redigido no idioma alemão e destinava-se, fundamentalmente, aos teuto-brasileiros, que compunham a maioria da população de Santa Cruz do Sul no início do século XX. Nas páginas do Kolonie, foram encontrados textos sobre Santa Cruz do Sul, localidades próximas e a Alemanha. Segundo Vogt (2001), eram publicados textos que exaltavam a identidade teuto-brasileira e o germanismo.

O jornal, também, divulgava informações sobre as diferentes associações teuto-brasileiras ${ }^{5}$ organizadas em Santa Cruz do Sul e localidades vizinhas, as quais além de atividades sociais e culturais, também promoviam práticas esportivas. Estas informações estão situadas em diferentes sessões do jornal, sem local específico como, por exemplo, em seções textuais ou em anúncios. No que se refere às notícias sobre as práticas esportivas, os termos empregados são distintos.

4 Esta pesquisa contou com auxílio financeiro de bolsa CNPq.

5 A expressão "teuto" refere-se à nacionalidade pela retórica de sangue comum, o jus-sanguinis, sendo alemão todo aquele que tem sangue alemão. Enquanto que o termo "brasileiro" estava associado à cidadania, pela concepção do jus-soli. Segundo Seyferth (1992), este termo é utilizado para designar os imigrantes e descendentes de alemães no Brasil. 
No Kolonie, o vocábulo sport (esporte) é encontrado pela primeira vez em uma notícia publicada no final do século XIX, no ano de 1896, quando o jornal fez referência às associações esportivas existentes na Alemanha, utilizando a denominação Sportliche Vereinigungen (associações esportivas) (DEUTSCHLAND, 1896). No entanto, as práticas esportivas vigentes em Santa Cruz do Sul no século XIX, como o tiro a alvo ${ }^{6}$, a cavalaria/ lançaria, o bolão e a ginástica (turnen), eram designadas apenas pela sua tradução no idioma alemão, sem qualquer referência ao termo sport (ASSMANN, 2015).

Em relação às práticas esportivas locais, este vocábulo foi utilizado somente a partir de 1900. Inicialmente, esteve associado às corridas de cavalo e ao turfe, fazendo-se presente no interior de notícias e em títulos de matérias. No entanto, não era uma expressão aplicada com frequência pelo jornal Kolonie, apresentando-se ainda de forma embrionária no cenário esportivo santa-cruzense.

Todavia, no início da década de 1910, o termo sport foi empregado de forma recorrente, referindo-se, especialmente, à emergência da prática do tênis e de clubes de futebol no município. Este estudo dedica, portanto, especial atenção para este período. Tais práticas esportivas são originárias da Inglaterra, assim como o termo inglês sport, adotado por diferentes países como um termo comum para designar tais manifestações, assim como na Alemanha (ELIAS, DUNNING, 1992) e em Santa Cruz do Sul no início do século XX (ASSMANN, 2015).

Diante de tais considerações, este estudo histórico busca responder ao objetivo proposto através da análise de reportagens do jornal Kolonie, coletadas desde a primeira edição no ano de fundação, 1891, até o ano de 1917, quando as atividades do jornal foram paralisadas devido aos acontecimentos que atravessavam o Brasil e o mundo no período em decorrência do conflito da Primeira Guerra Mundial (1914-1918). Quando o Brasil ingressou na I Guerra Mundial, em 1917, o Kolonie paralisou suas edições por, aproximadamente, dois anos. Neste período, os editores veicularam outro jornal, chamado Gazeta Santa Cruz, redigido em língua portuguesa (MARTIN, 1999). De tal modo, podemos inferir que os editores do Kolonie eram conhecedores da língua portuguesa, no entanto elegeram o idioma alemão, especificamente o alemão gótico, como oficial à redação do jornal até 1941, ano de seu fechamento ${ }^{7}$.

No período demarcado para fins deste estudo, os relatos sobre eventos esportivos no jornal Kolonie eram, geralmente, enviados ao jornal por correspondência. Assim, eram notícias produzidas pelos próprios dirigentes das associações esportivas, mas que nem sempre eram publicadas na íntegra. Notícias de outros jornais do Rio Grande do Sul também eram veiculadas pelo Kolonie, após serem traduzidas para o idioma alemão.

Exemplares deste jornal encontram-se no Centro de Documentação da Universidade de Santa Cruz do Sul (CEDOC UNISC) e, para o registro das informações, as

6 Para mais informações ver Assmann e Mazo (2012).

7 Após dois anos de paralisação, o jornal voltou a ser veiculado até o ano de 1941, quando encerrou suas atividades em decorrência de medidas adotadas na campanha de nacionalização instituída durante o Estado Novo (1937-1945) no governo de Getúlio Vargas. 
reportagens foram fotografadas seguindo as técnicas e cuidados orientados por Bacellar (2010). Salienta-se que as fontes coletadas no jornal Kolonie estavam originalmente em alemão e foram traduzidas para o português a fim de facilitar a compreensão desse estudo. Ainda, cabe referir que o jornal não apresenta paginação. Após a coleta e fichamento das reportagens, as fontes foram submetidas à análise documental (BACELLAR, 2010) e cotejadas com a revisão bibliográfica e o referencial teórico.

Este estudo pretende contribuir para a construção de versões históricas, através dos vestígios deixados pelos homens do passado, dialogando com os pressupostos teóricos desenvolvidos por historiadores culturais (CHARTIER, 2000; PESAVENTO, 2004; BURKE, 2005). Os estudos históricos e socioculturais abordam significados construídos por grupos particulares, em locais e períodos específicos; grupos estes que sofrem transformações e adaptações de acordo com as novas circunstâncias (BURKE, 2005). No caso deste estudo, busca-se apresentar uma versão sobre como um jornal veiculava notícias sobre o esporte, em um determinado tempo histórico e contexto, negociando práticas e representações culturais identitárias que, também, atravessavam o campo esportivo.

\section{SPORT: UMA PRÁTICA SAUDÁVEL E MODERNA NO TEXTO DO JORNAL KOLONIE}

Em meados da década de 1910 verificamos a produção de um novo discurso no jornal Kolonie, relacionado com as novas práticas esportivas emergentes, o tênis e o futebol, além de reconfigurações na prática do Turnen (ginástica). Tal discurso vinculava o sport às concepções de modernidade e saúde. No período, observa-se em Santa Cruz do Sul um incipiente processo de modernização por meio da instalação da iluminação pública e privada, construção da Estação Férrea e, crescente circulação de automóveis nas ruas. Conforme Martin (1999), a localidade, antes calma e pacata, estava se modernizando.

A introdução de novas práticas esportivas também indicava mudanças no panorama da cidade. Em Santa Cruz do Sul, a prática do futebol ${ }^{8}$ foi, provavelmente, introduzida pela Turnverein (Sociedade de Ginástica), em 1905 (ASSMANN, 2015). Entretanto, não encontramos muitas referências sobre esta prática ao longo da primeira década do século XX. O futebol começou a aparecer no jornal Kolonie de forma contundente após o ano de 1910. Há registro da atuação de seis associações voltadas para a prática do futebol no ano de 1914: Fussballverein Handweg (Sociedade de Futebol Handweg), Footballclub Santa Cruz (Futebol Clube Santa Cruz), Sportklub 15 de Novembro (Clube Esportivo 15 de Novembro), Sportclub 7 de Setembro (Clube Esportivo 7 de Setembro), Gremio Santacruzense e Duque de Caxias. Não foi possível apurar as datas de fundação dos demais clubes supracitados com exceção do Futebol Clube Santa Cruz, institucionalizado em 1913. Este clube foi fundado por um grupo de jovens com sobrenomes, majoritariamente, germânicos. Reunidos no Hotel Schmidt, no dia 26 de março de 1913, os jovens, especialmente

8 O futebol é um esporte coletivo sistematizado pelos ingleses, em 1863, com a denominação de association football. Sua difusão mundial aconteceu a partir de 1890 (MASCARENHAS, 2001). 
convidados pelo idealizador do clube, André Klarmann, imigrante alemão recém-chegado na cidade, instituíram o clube e escolheram a direção da associação: André Klarmann como presidente e Ernst Frantz como vice-presidente (FOOT-BALL..., 1913).

Na publicação referente à fundação do clube é exaltada a prática do futebol na Europa como justificativa não apenas para a criação, mas para o progresso da associação esportiva em Santa Cruz do Sul. Ainda, no texto é destacada a Inglaterra como inventora do esporte e as iniciativas dos ingleses para disseminar a prática: "No ano passado a cidade de Londres distribuiu não menos de 50.000 Mark em diferentes sociedades esportivas, para sempre fornecer vida animada para as associações" (FOOT-BALL..., 1913). Os franceses também são citados pela forma como tratam o futebol: "o chamam de bom para tudo e protegem ele da melhor forma" (FOOT-BALL..., 1913). Ainda, alude que entre os estudantes alemães e holandeses, nas escolas e universidades, o jogo de futebol já era prática corrente: "foram encontrados não menos que 17 "Matches", os quais o povo compartilhou com aplausos". Por fim, a publicação estima que as informações "possam ser um "audacioso avante" para a nova associação e que ela as pegue como exemplo" (FOOT-BALL..., 1913).

Nota-se que são atribuídas representações de civilização moderna à Europa, sugerindo-se que as conformações europeias sejam apreendidas como modelo de um novo ideário: "ser moderno". Associado a tais compreensões, constatamos, no decorrer do mesmo texto, o ideal de saúde agregado como inerente à prática do futebol. O jogo é retratado como "uma grande vantagem para os jovens", um remédio capaz de prevenir e curar doenças (FOOT-BALL..., 1913). "Não raro se teve a experiência, de pessoas já fracas e doentes recuperarem sua condição através do jogo de futebol". Dentre os motivos destacados na matéria considera-se que "o esporte e o fortalecimento [...] é um importante meio de higiene e de prevenir doenças, como nenhum outro" (FOOT-BALL..., 1913).

O autor do texto se apropria de uma visão científica e higienista para enobrecer a prática esportiva. Este discurso pairava no cenário brasileiro no início do século XX, pois havia a preocupação da elite econômica e política com a formação da nação brasileira. Segundo Góis Junior; Lovisolo (2003, p. 42): “um novo ideal cujo eixo era a preocupação com a saúde da população, coletiva e individual. Suas propostas residiam na defesa da saúde e educação pública e no ensino de novos hábitos higiênicos".

A prática esportiva como instrumento para a concretização do novo ideal de saúde, conforme evidenciado no texto acima, era aplicada aos discursos presentes no jornal Kolonie sobre o associativismo esportivo santa-cruzense, no início da década de 1910. Cabe ressaltar que ao final da publicação encontramos as letras "A." e "K.", as quais possivelmente referem-se a André Klarmann", sócio fundador do clube. Esta informação revela que entre os sócios fundadores do clube, a compreensão do sport enquanto elemento "saudável" e "moderno" estava presente.

O discurso higienista foi encontrado também em outras publicações referentes ao futebol, geralmente, conectadas a um torneio próximo. As associações de futebol

9 Este professor que trabalhou no colégio Deutsche Synodal Schule (Colégio Alemão Sinodal), atual Colégio Mauá em Santa Cruz do Sul, compreendia quatro idiomas: alemão, português, francês e inglês (SPRACHEN, 1915). 
promoviam campeonatos e convidavam outras associações de futebol de Santa Cruz e de localidades próximas, como Rio Pardo e Candelária. Ao divulgar tais eventos propagavam concepções relacionadas ao "fortalecimento da vontade e do autocontrole", "vitalidade esportiva", "exercício corporal", "festa ao ar livre" (SPORT UND SPIEL, 29 abr. 1914; SPORT UND SPIEL, 18 maio 1914).

De acordo com Wink (2000), no início do século XX, o governo de Santa Cruz do Sul estava imbuído do "espírito higienista". A preocupação com a saúde da população resultou na criação do Hospital Oficial de Santa Cruz do Sul, em $1908^{10}$. A direção técnica do hospital ficou a cargo de Heinz von Ortenberg, médico alemão recém chegado à Santa Cruz do Sul (TELLES, 1980), e que, possivelmente, agiu como propagador de concepções higienistas. Não por acaso, Heinz von Ortemberg foi um dos idealizadores do Tennis Club Waldmeister, fundado em 1910 em Santa Cruz do Sul (Imagem 1).

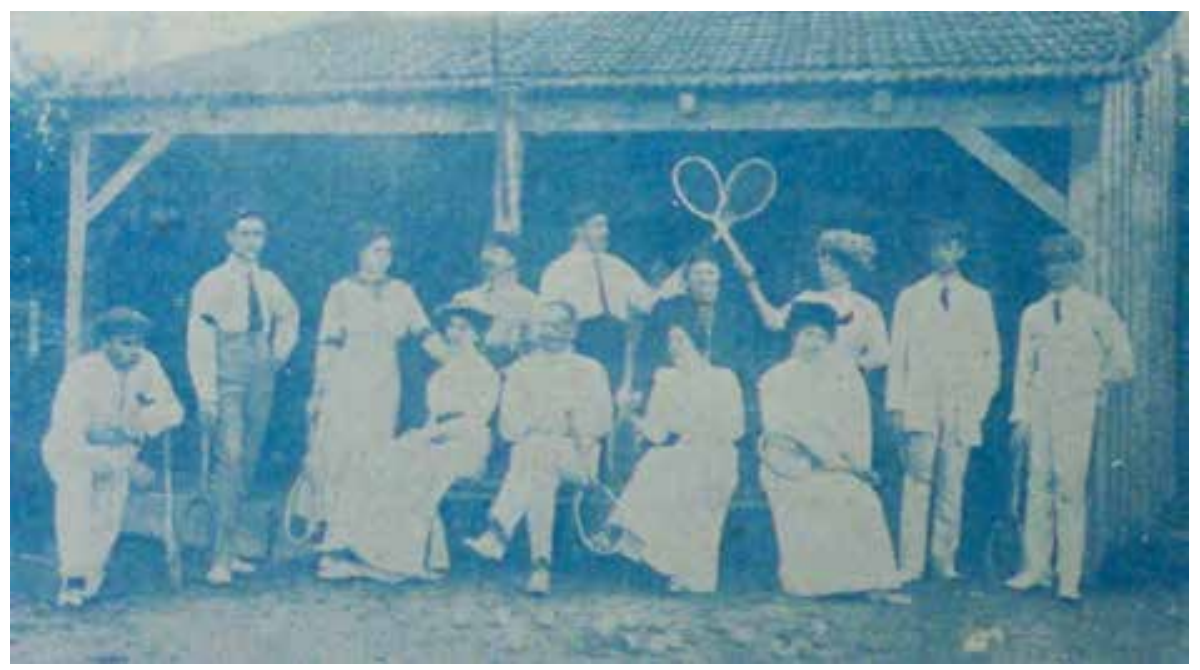

Imagem 1 - Grupo de tenistas do Tennis

Club Waldmeister, em 1911 (SANTA CRUZ..., 1940).

Segundo o Kolonie, o clube de tênis "coloca como principal a promoção e desempenho de um corpo saudável, mas também a atividade mental estimulada pelo Tennis" (LAWNTENNIS-CLUB..., 1910). A defesa pelos princípios higiênicos está representada na frase "mens sana in corpore sano", ou seja, o cuidado com o corpo não estava atrelado somente ao fortalecimento orgânico do individuo, mas, também, ao fortalecimento mental e moral. Estas percepções são também observadas na publicação realizada pelos associados do clube de tênis, afirmando que a finalidade da associação consiste na manutenção do "nobre exercício do corpo" (DIE MITGLIEDER...., 1910).

10 Na época já havia organizações particulares para auxiliar os doentes e o Sanatório Kampf, fundado em 1885. 
O Tennis Club Waldmeister11 foi o primeiro clube em Santa Cruz do Sul a congregar homens e mulheres simultaneamente na prática. Além de sócias fundadoras, as mulheres também participavam ativamente, e lado a lado, com os homens nos jogos propriamente ditos (Imagem 2). Isto é evidenciado em fotografias e na notícia referente ao torneio interno de aniversário da associação, no qual foram distribuídos quatro prêmios, sendo o segundo lugar conquistado pela associada Adelina Heuser (SPORT UND SPIEL, 14 maio 1913). Os demais vencedores eram todos homens.

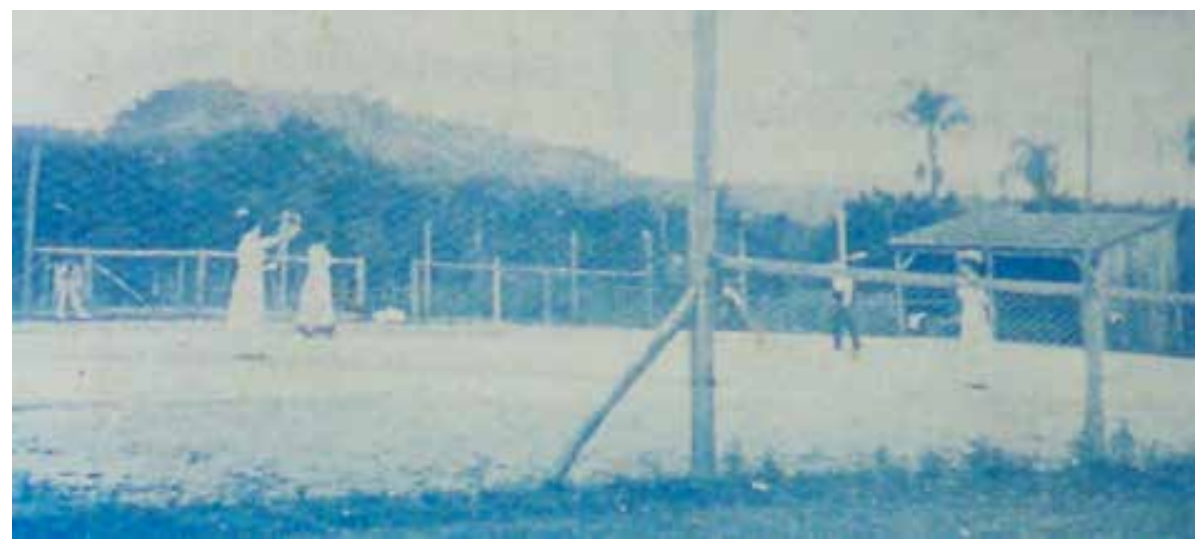

Imagem 2 - A primeira quadra de tênis do Tennis Club Waldmeister, em 1911 (SANTA CRUZ..., 1940).

Seis meses após a fundação do clube, em junho de 1910, foi construída a primeira quadra de tênis, em terreno cedido por Gaspar Bartholomay (TÊNIS..., 1960). Em 1914, no ano que eclodiu a Primeira Guerra Mundial, o clube mudou o nome original do idioma alemão para Tennis Sport Club Santa Cruz e, em 1921, retirou o termo Sport da denominação e passou a ser chamado de Tennis Club Santa Cruz (TÊNIS..., 1960; SANTA CRUZ..., 1940), como permanece até hoje, porém na tradução para a língua portuguesa: Tênis Clube Santa Cruz.

As mudanças na denominação do clube de tênis indicam interesses de assinalar a distinção pela apropriação de representações culturais estrangeiras e "modernas". No princípio, o clube de tênis Waldmeister era um espaço restrito aos fundadores, cujo limite estipulado era 20 sócios. Contudo, poucos anos depois da fundação, as modificações apontadas revelam que fora desencadeada uma ruptura, pelo menos no campo das representações culturais do clube.

A nova representação do clube de Tênis certamente foi apreciada pelos santa-cruzenses e pelo jornal Kolonie, que na época da fundação tinha manifestado

11 A associação para a prática do tênis em Santa Cruz do Sul foi fundada com a denominação Waldmeister. A justificativa para tal denominação, conforme o Livro Comemorativo dos 50 anos do clube, é que na ocasião da fundação foi servida uma bebida chamada "Bowle Waldmeister", sendo sugerida, e aprovada, tal designação. 
descontentamento com a situação. No anúncio sobre a criação do clube, os redatores criticaram a restrição numérica de associados, embora fossem identificados como representantes "do melhor círculo da sociedade". O texto, na parte final, apontou sutilmente a posição dos redatores: "tomara que o clube seja bem sucedido, e que traga a alegria do esporte também a outros círculos" (LAWNTENNIS-CLUB..., 1910). Essa afirmação, seguramente, não estava se referindo a pessoas menos favorecidas economicamente, mas, sim, aos indivíduos com boas condições econômicas que também gostariam de desfrutar de um espaço social de distinção como o do clube de tênis. Os associados, entretanto, se ofenderam com a publicação e responderam em nota ao jornal, justificando a participação limitada de pessoas devido às próprias características do jogo de tênis. Além disso, anotou que estavam abertos para a entrada de novos integrantes, "amantes do esporte", tão logo o espaço fosse ampliado (DIE MITGLIEDER...., 1910).

\section{SPORT: APROXIMAÇÕES E DISSONÂNCIAS NO KOLONIE}

O discurso do sport alcançou a Turnverein, em 1914: "é de conhecimento que o Turnen e o sport pertencem um ao outro e devem ser cultivados juntos. Tendo isso em vista a Turnverein Santa Cruz pretende proporcionar aos seus associados oportunidades de ações esportivas" SPORTLEBEN, 13 jul. 1914). O fragmento acima foi extraído de um texto que anuncia o novo local para a Turnverein realizar jogos ao ar livre, as terras do Sr. Hermann Pittelkow, próximo do terreno onde era jogado futebol pelos associados do clube 15 de Novembro (SPORTLEBEN, 13 jul. 1914). Outro indício da presença do sport na Turnverein foi a introdução de novas práticas, como a esgrima, o punhobol e o tamburinball12, tanto para os homens quanto para as mulheres ${ }^{13}$ (FESTSCHRIFT..., 1929; SPIEL UND SPORT, 4 maio 1914; SPORTLEBEN, 13 jul. 1914). A escolha de tais práticas, talvez seja uma tentativa de aproximação com as concepções atreladas ao sport. Ou, pode significar uma forma de resistência da Sociedade de Ginástica aos esportes idenficados como sendo "ingleses".

Neste período, as notícias a respeito do Turnen, tênis e futebol começam a aparecer sob os títulos Sportleben (vida esportiva) e Spiel und Sport. Nestas expressões observamos uma dupla representação, a alemã nas palavras Leben (vida) e Spiel (jogo) e a inglesa no termo sport (esporte). Isso permite evidenciar a produção de sentidos próprios de uma nova configuração, que um grupo de pessoas, como os editores do jornal e líderes de associações esportivas, buscava propagar na sociedade santa-cruzense.

A apropriação do sport enquanto elemento que deveria ser reproduzido e disseminado pelo jornal foi, provavelmente, determinante para a criação de uma sessão exclusiva

12 Tamburinball é um jogo que surgiu na Itália e foi apropriado como prática esportiva pelas Turnvereine da Alemanha, especialmente como prática para as mulheres. No alemão a tradução é Trommelball. Este jogo é semelhante ao tênis e ao punhobol, porém no lugar da raquete ou da mão se utiliza um objeto semelhante a um pandeiro. A bola utilizada é pequena e elástica (WAGNER, 1913). 
para a divulgação de notícias esportivas, intitulada Sport-Zeitung (Jornal de Esportes). Segundo os redatores do Kolonie, esta sessão foi criada devido ao crescimento significativo de diferentes modalidades esportivas no país e seria dedicada às sociedades locais e aos eventos sobre a vida esportiva do mundo (SPORT-ZEITUNG, 1914).

No espaço Jornal de Esportes foram encontradas matérias sobre a ginástica nos Jogos Olímpicos (TURNWESEN, 1914), a importância do treinamento para o desempenho esportivo (TRAINING, 1914), os campeonatos de futebol (FUSSBALLWETTSPIEL, 1914; WETTSPIEL, 1914) e a aviação (HELMUTH..., 1914), corroborando com as percepções de modernidade no discurso esportivo. No entanto, tal sessão teve vida efêmera no jornal, sendo retirada da redação em agosto daquele ano. É possível que o espaço antes destinado exclusivamente ao esporte, tenha sido ocupado pelas matérias que traziam notícias sobre a I Guerra Mundial, que iniciava no período.

Para além das chamadas no jornal, a apropriação de termos ingleses é também observada em expressões como sportmen e matches, incluídos no vocabulário dos clubes de futebol. Conforme Santos (2009, p. 184), a concepção de sportmen estava relacionada "aos filhos das famílias ricas dos centros urbanos que carregavam condições e valores, reais e simbólicos, bem definidos, e, sobretudo, que convergiam para a modernidade". Franzini (2009, p. 118) associa a adequação de representações culturais "importadas da Inglaterra", como o vocabulário específico e o uniforme, enquanto traços de distinção social, no caso "expressões do elitismo" dos praticantes. Na publicação sobre o Foot-ball Clube Santa Cruz, possivelmente escrita pelo próprio presidente do clube, a revelação de um espaço diferenciado através da prática do futebol é evidenciado quando os jogadores são qualificados como "bravos sportmen" que vestem seus "elegantes trajes" no domingo à noite (FOOT-BALL..., 1913).

Os matches (partidas) do mesmo clube eram muitas vezes anunciados com grandes imagens ilustrativas dos jogos de futebol (Imagem 3). O uso de imagens no jornal foi também verificado em anúncios de associações de tiro ao alvo, cavalaria e Turnen, bem como, na programação do turfe e, algumas vezes, no bolão. No entanto, eram imagens que traziam signos representativos das práticas como, por exemplo, o alvo e armamentos usados no tiro ao alvo e o símbolo dos quatro $\mathrm{Efes}^{14}{ }^{14}$ o qual está relacionado ao lema compartilhado pelas associações de Turnen.

A imagem utilizada para representar simbolicamente o jogo de futebol no jornal superava, em tamanho e detalhes, as demais publicações. A imagem ilustrava a prática propriamente dita, composta por homens em atuação no jogo, e, certamente, pretendia ressaltar a prática esportiva e o clube. Tais particularidades podem indicar um aporte financeiro diferenciado, com certa influência, assim como, o desejo de afirmar uma posição social. Cabe salientar a presença unânime de imagens de jogadores brancos, construindo significados sociais, dando-se a ler enquanto um espaço delimitado a certos grupos. As imagens referentes aos torneios de futebol ilustravam o sport e suas significações naquele período específico.

14 Frisch (vigoroso), Fromm (devoto), fröhlich (alegre), frei (livre) (KRÜBER, 2011). 


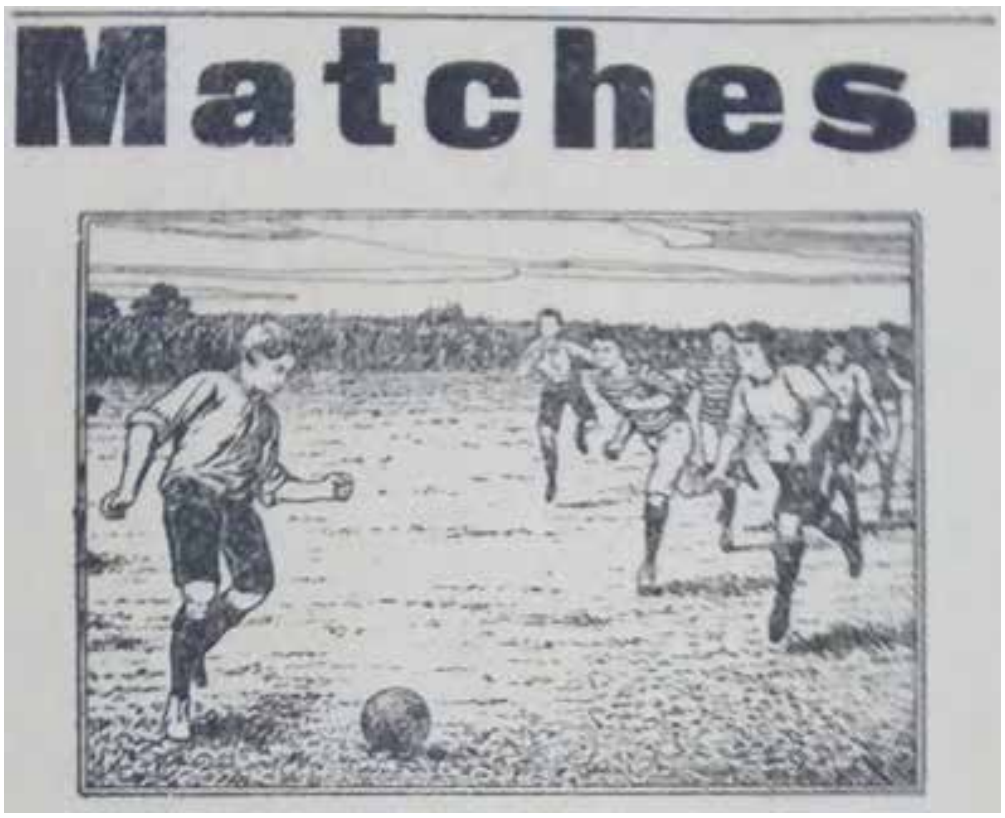

Imagem 3 - Ilustração em anúncio de um torneio de futebol no jornal Kolonie (MATCHES, maio 1914)

O termo sport também começa a aparecer na denominação de clubes: Sportklub 7 de Setembro; Sportklub 15 de Novembro e Tennis Sport Club Santa Cruz (originalmente chamada Waldmeister) (SANTA CRUZ..., 1940). Todavia, a apropriação de tais expressões inglesas no associativismo esportivo não sucedeu sem ressalvas e oposições. No mesmo dia em que foi publicado o texto referente a fundação do Foot-ball Club Santa Cruz, em 1913, foi também editorado um texto de M. Rau, no qual o autor condena a utilização de termos em inglês nas associações esportivas de Santa Cruz do Sul (SPRACKECKE..., 1913).

O editor do jornal, a despeito de considerar o futebol um "antídoto contra muitas influências prejudiciais", uma proteção para a saúde dos jovens, também se declara contra o "inglesamento" de "associações esportivas alemãs", referindo-se a associações teuto-brasileiras (SPORT UND SPIEL, 5 maio 1913). Afirma que no Brasil existem duas línguas mães, o alemão e o português: "uma obrigação dupla de honrar os dois idiomas, assim nós nos esforçamos para que elas dominem em total beleza e não se desconfigurem através da mistura de palavras estrangeiras" (SPORT UND SPIEL, 5 maio 1913).

Tais testemunhos evidenciam que, apesar do discurso pela saúde aparecer de forma contundente, existia resistências em outros aspectos, como na questão do idioma. O campo esportivo (BOURDIEU, 2003) em Santa Cruz do Sul também era espaço de disputas, de lutas sociais. Na situação apontada acima o que estava "em jogo" era a legitimação do campo esportivo enquanto espaço teuto-brasileiro. 
O Sport Club 15 de Novembro, cujo nome utiliza uma expressão inglesa e faz alusão a uma data cívica brasileira, apresentava seus anúncios nos dois idiomas: português e alemão (A COMISSÃO, 1914). A dupla representação, possivelmente, visava abarcar os indivíduos luso-brasileiros e teuto-brasileiros que participavam do clube. Isto é também evidenciado em outra publicação, na qual o 15 de Novembro recusa o convite do Sportklub 7 de Setembro para um torneio devido ao conflito da Primeira Guerra Mundial que afetava os "dois povos" (SPORTLEBEN, 21 ago. 1914). Os povos referiam-se aos cidadãos de Portugal e da Alemanha.

Em uma edição do jornal Kolonie, publicada no início do ano de 1914, havia informações referentes à prática do futebol, as quais foram extraídas de um texto escrito no jornal "O Rio Grande" sobre um jogo em Cachoeira, localidade que, possivelmente, refere-se a Cachoeira do Sul. Neste texto, o futebol é considerado como "uma doença contagiosa" que afetava toda a cidade. O jornal "O Rio Grande", registrou em suas páginas um pedido de auxílio às autoridades locais a fim de evitar acidentes devido à utilização de ruas para o "jogo com bola". O Kolonie, apesar de concordar com a preocupação referida, exaltava o futebol como prática esportiva para os jovens, manifestando sua apreciação para com o jogo (UEBER..., 1914).

"Ataques", no entanto, acionavam táticas defensivas. Sobre um campeonato promovido pelo Sportklub 15 de Novembro, com a participação das associações Spiessbraten Waldmeister e o clube de futebol 7 de Setembro, foi divulgado um relato escrito por um membro da associação sede. Neste, um parágrafo é dedicado para exaltar o exemplar campeonato e comportamento dos jogadores, em contraponto aos "hostis presságios" que rondavam a nova prática esportiva (M. VOM QUINZE, 15/5/1914).

Outra reportagem, publicada na sessão específica de notícias esportivas - Sport-Zeitung - enfatiza as disputas dentro do próprio campo de jogo e permite reflexões para além deste espaço. Essa notícia aborda um campeonato composto de dois jogos, entre os clubes de futebol Santa Cruz e Rio Pardense, oriundo da localidade vizinha, Rio Pardo, cidade colonizada por portugueses. A narrativa apresentada na reportagem permite observar intencionalidades e interesses envolvidos na divulgação da notícia, com argumentos que favorecem o time de Santa Cruz. Quanto ao jogo ganho, foi relatada a irritação dos oponentes em disparidade com o comportamento dos santa-cruzenses. Enquanto a derrota vinha enumerada de justificativas, como o vento, a sorte, um gol feito com a mão e os cinco jogadores de Porto Alegre disputando pelo time do Rio Pardense. Ainda segundo a reportagem, os jogadores do clube Santa Cruz fizeram valer os seus direitos através da figura do árbitro, apresentado como aquele que deveria manter a paz e ordem no jogo (FUßBALLWETTSPIEL, 24 jun 1914).

\section{CONSIDERAÇÕES FINAIS}

A investigação sobre as concepções do termo sport (esporte) veiculadas pelo Kolonie, desde a fundação até o ano de 1917, quando o jornal interrompe suas atividades, 
evidenciou que o termo foi empregado de forma distinta no período estudado. O termo sport foi veiculado pelo jornal Kolonie diferenciando práticas esportivas das tradicionais práticas culturais teuto-brasileiras. As primeiras apropriações do termo sport no jornal foram associadas à prática das corridas de cavalo.

O discurso sportivo ganhou força na década de 1910, por meio da divulgação de práticas esportivas emergentes no cenário santa-cruzense: o tênis e o futebol. O sport, termo inglês utilizado pelo jornal, foi apropriado enquanto representação de uma prática saudável e moderna. Tais representações estavam relacionadas ao contexto sociocultural e às predicações que envolviam o país naquele período.

Nas notícias sobre as práticas esportivas manifestavam-se concepções higienistas, como também se percebeu comparações e menção a exemplos no mundo europeu, apontado como moderno. O tênis e, notadamente, o futebol foram imbuídos de premissas que pregavam a saúde corporal a partir de concepções médico científicas. Esta prática cultural deveria ser consumida como "remédio", um antídoto e uma prevenção contra os males que acometiam um corpo "fraco".

As novas práticas e os novos discursos que atravessavam o associativismo esportivo santa-cruzense provocaram reconfigurações em tradicionais associações, como foi o caso da Turnverein. Na mesma década, 1910, a sociedade de ginástica criou o departamento feminino e introduziu novas práticas esportivas, aludindo, por meio destas admissões, a aproximação com o conceito de sport. De tal modo, nota-se que as mulheres foram inseridas no campo esportivo, mas este não foi o único caminho consentido e conquistado por elas.

No entanto, estas aproximações não foram aceitas sem ressalvas. A utilização de termos em inglês no contexto do associativismo esportivo em Santa Cruz do Sul foi alvo de protestos no jornal. As práticas esportivas, para determinado grupo, deveriam manifestar uma identidade teuto-brasileira, especialmente, através da manutenção do idioma. No entanto, as contestações parecem não ter alcançado grande repercussão, pois o inglês foi empregado cada vez com mais frequência, relacionado, especialmente, à prática do futebol e ao crescente número de clubes voltados para esta modalidade.

O sport conquista uma seção exclusiva no jornal Kolonie, em 1914. Apesar do curto período de vigência, a criação da Sport-Zeitung e os textos nesta divulgados evidenciam a construção - ou reconstrução - de significados em torno das práticas esportivas e suas emergentes concepções. Os novos sports introduzidos no cenário do associativismo santa-cruzense e veiculados pelo periódico estavam carregados de discursos socioculturais que os diferenciavam das práticas esportivas vinculadas a representações identitárias teuto-brasileiras e os aproximava de concepções de um ansiado novo tempo. No entanto, tais conjunturas foram também espaços de disputas étnicas e sociais, dentro e fora do campo de jogo. A partir das reportagens analisadas, pode-se depreender que existiam aproximações e dissonâncias no campo esportivo santa-cruzense. E, que o Kolonie era utilizado, também, como canal de embates, apresentando narrativas parciais, que desvelam intencionalidades, contrapondo-se ao princípio da imparcialidade cobiçado atualmente. 


\section{REFERÊNCIAS}

A COMISSÃO, Kolonie, Santa Cruz do Sul, nov. 1914.

ASSMANN, A.B. O associativismo esportivo em Santa Cruz do Sul/ Rio Grande do Sul: configurações de práticas culturais (da década de 1880 à década de 1910). 2015. 151f. Dissertação (Mestrado em Ciências do Movimento Humano) - Escola de Educação Física, Fisioterapia e Dança da UFRGS, Porto Alegre, 2015.

ASSMANN A.B., MAZO J.Z. As Schützenvereine - Sociedades de Atiradores - de Santa Cruz do Sul: um tiro certo na história do esporte no Rio Grande do Sul. Esporte e Sociedade, ano 7, n. 20: 2012, p. 122-53.

BACELLAR, C. Fontes documentais: uso e mau uso dos arquivos. In: PINSKI, C. (Org.). Fontes históricas. São Paulo: Contexto, 2 ed., 2010, p. 23-80.

BOURDIEU, P. Como se pode ser desportista? In.: BOURDIEU, P. Questões de sociologia. Lisboa: Fim de Século, 2003.

BURKE P. O que é história cultural? Rio de Janeiro: Zahar, 2005.

CHARTIER, R. A história cultural: entre práticas e representações. Lisboa: DIFEL; Rio de Janeiro: Bertrand Brasil, 2000.

DEUTSCHLAND. Kolonie, Santa Cruz do Sul, 23 maio 1896.

DIE 1. ORDENTL. GENERALVERSAMMLUNG der Gesellschat "Kolonie“. Kolonie, Santa Cruz do Sul, 10 jan. 1891.

DIE MITGLIEDER des Tennisclub. Kolonie, Santa Cruz do Sul, 15 fev. 1910.

ELIAS, Norbert; DUNNING, Eric. A busca da excitação. Lisboa: Memória e Sociedade, 1992.

ENTWICKLUNGS-GECHICHTE des Tennis Club Waldmeister, Santa Cruz. Caderno de Atas, 09 jan. 1910.

FESTSCHRIFT von der VII Turnfest der Turnerschaft von Rio Grande do Sul. Livro Comemorativo. Porto Alegre: Martin Fischer, 1929.

FOOT-BALL Club Sta. Cruz. Kolonie, Santa Cruz do Sul, 05 maio 1913.

FRANZINI, F. A futura paixão nacional: chega o futebol. In: DEL PRIORE, M.; MELO, V. (orgs). História do Esporte no Brasil: do império aos dias atuais. São Paulo: Editora UNESP, p. 107-131, 2009.

FUSSBALLWETTSPIEL. Kolonie, Santa Cruz do Sul, 29 jun. 1914.

GÓIS JUNIOR, E.; LOVISOLO, H. R. Descontinuidades e continuidades do Movimento Higienista no Brasil do século XX. Revista Brasileira de Ciências do Esporte, Campunas, v. 25, n. 1, p. 41-54, 2003.

HELMUTH Hirth in Dichtung und Wahrheit. Kolonie, Santa Cruz do Sul, 01 jul. 1914. HOHFELDT, A. A imprensa sul-rio-grandense entre 1870 e 1930. Compós, Revista da Associação Nacional dos Programas de Pós-Graduação em Comunicação, dez 2006. KRÜGER, M. Turnen na Alemanha - do movimento nacional de uma cultura física e motora ao moderno movimento do esporte de lazer. In: Tesche L. Turnen: transformações de uma cultura corporal européia na América. Ijuí: Editora Unijuí, 2011.

LAWNTENNIS-CLUB Waldmeister. Kolonie, Santa Cruz do Sul, 08 fev. 1910. 
MARTIN, H. E. Recortes do passado de Santa Cruz. Organizado e atualizado por Olgario Paulo Vogt e Ana Carla Wïnsch. Santa Cruz do Sul: Edunisc, 1999.

MASCARENHAS G. A Bola nas Redes e o Enredo do Lugar: uma geografia do futebol e de seu advento no Rio Grande do Sul. 2001. Tese (Doutorado) - Universidade de São Paulo, São Paulo, 2001.

MATCHES. Kolonie, Santa Cruz do Sul, maio 1914.

M. VOM QUINZE. Kolonie, Santa Cruz do Sul, 31 ago. 1914.

PESAVENTO, S. J. História \& História Cultural. 2a ed. Belo Horizonte: Autêntica, 2004. SANTA CRUZ Sportivo. Tennis Clube Santa Cruz: esboço histórico, out. 1940.

SANTOS, R. P. dos. Tensões na consolidação do futebol nacional. In: DEL PRIORE, M.;

MELO, V. (orgs). História do Esporte no Brasil: do império aos dias atuais. São Paulo:

Editora UNESP, p. 179-212, 2009.

SEYFERTH, G. Etnicidade e cultura: a constituição da identidade teuto-brasileira. In.: ZARUR,

G. C. L (Org.). Etnia y Nación en América Latina. INTERAMER, n.45, vol.II, 1992.

SPIEL UND SPORT. Kolonie, Santa Cruz do Sul, 04 maio 1914.

SPORTLEBEN. Kolonie, Santa Cruz do Sul, 13 jul. 1914.

SPORT UND SPIEL. Kolonie, Santa Cruz do Sul, 29 abr. 1914.

SPORT UND SPIEL. Kolonie, Santa Cruz do Sul, 14 maio 1913.

SPORT UND SPIEL. Kolonie, Santa Cruz do Sul, 18 maio 1914.

SPORT-ZEITUNG. Kolonie, Santa Cruz do Sul, 08 jun. 1914.

SPORTLEBEN. Kolonie, Santa Cruz do Sul, 21 ago. 1914.

SPRACHECKE des Allgemeinen Deutschen Sprachvereins. Kolonie, Santa Cruz do Sul,

05 maio 1913.

TÊNIS Clube Santa Cruz: em seu cinquentenário (1910-1960). Dados históricos do Tenis

Clube Santa Cruz, 30 maio 1960.

TRAINING. Kolonie, Santa Cruz do Sul, 08 jun. 1914.

TURNVEREIN. Kolonie, Santa Cruz do Sul, 1910 jul. 26.

TURNWESEN, Kolonie. Santa Cruz do Sul, 08 jun. 1914.

VOGT, O. P. Imperialismo: a face oculta do germanismo. In: Centro de Estudos Marxistas.

As portas de Tebas: ensaios de interpretação marxista. Ágora, Santa Cruz do Sul, v. 7,

n. 2 p. 49-92, jul. dez. 2001.

UEBER den Unfug des Fussballspiels auf der Strasse. Kolonie, Santa Cruz do Sul 14 jan. 1914. WESCHENFELDER, G. A imprensa alemã no Rio Grande do Sul e o romance-folhetim.

2010. 146 f. Dissertação (Mestrado em Comunicação Social) - Faculdade de Comunicação Social, Pontifícia Universidade Católica do Rio Grande do Sul, Porto Alegre, 2010.

WETTSPIEL. Kolonie, Santa Cruz do Sul, 13 jul. 1914.

WINK, R. Santa Cruz do Sul e sua Evolução Urbana: 1855 - 2000. 2000. 269 f. Dissertação

(Mestrado em Desenvolvimento Regional) - Universidade de Santa Cruz do Sul, Santa Cruz do Sul, 2000. 